\title{
Studi Pengaruh Longshore Current Terhadap Abrasi di Pantai Moro, Kabupaten
}

\author{
Kendal, Jawa Tengah
}

\author{
Wita Melisa $^{1 *}$, Hariyadi ${ }^{1}$, Sugeng Widada ${ }^{1}$, Elis Indrayanti ${ }^{1}$, Denny Nugroho Sugianto ${ }^{1}$, \\ Dwi Haryo Ismunarti ${ }^{1}$, Muh Yusuf ${ }^{1}$
}

\author{
Departemen Oseanografi, Fakultas Perikanan dan Ilmu Kelautan, Universitas Diponegoro Jl. Prof. H. Sudarto, \\ SH, Tembalang Semarang. 50275 Telp/fax (024)7474698 \\ Email:*witamelisa11@gmail.com
}

\begin{abstract}
Abstrak
Gelombang yang berasal dari laut dalam akan merambat menuju perairan dangkal dan mengalami perubahan, salah satunya membentuk gelombang pecah yang dipengaruhi oleh berkurangnya kedalaman. Gelombang pecah yang membentuk sudut terhadap garis pantai akan menimbulkan longshore current (arus sejajar pantai). Longshore current akan mengakibatkan tertranspornya sedimen di sepanjang pantai yang dapat menyebabkan terjadinya abrasi atau sedimentasi. Tujuan dari penelitian ini adalah untuk mengetahui mengetahui pengaruh longshore current terhadap abrasi yang terjadi di Pantai Moro. Materi yang digunakan pada penelitian ini menggunakan data primer dan data sekunder. Data primer yang digunakan yaitu tinggi dan periode gelombang lapangan dan sedimen dasar. Sedangkan data sekunder menggunakan data angin ECMWF selama 10 tahun, Citra Landsat 7 dan 8, data debit sungai dan data pasang surut. Penentuan pengukuran gelombang lapangan dan lokasi sampel sedimen menggunakan metode purposive sampling. Untuk meramalkan tinggi dan periode gelombang pada setiap musimnya menggunkan metode SMB (Svendrup Munk Metode Bretchheider), dan untuk menghitung laju abrasi menggunakan metode DSAS. (Digital Shoreline Analysis System). Berdasarkan hasil penelitian menunjukkan kecepatan longshore current pada musim barat sebesar $1,25038 \mathrm{~m} / \mathrm{s}$, pada musim peralihan 1 sebesar $0.71639 \mathrm{~m} / \mathrm{s}$, pada musim timur sebesar $1,08519 \mathrm{~m} / \mathrm{s}$, dan pada musim peralihan 2 sebesar 1,00732 m/s, yang menyebabkan abrasi dari tahun 2015-2016 seluas 7,29 ha.
\end{abstract}

Kata Kunci: Longshore Current, Abrasi, DSAS, Pantai Moro.

\section{Abstract}

The waves which moves from deep sea into shallow water then changed into breaking waves that affected by decrease of the depth. The angel made from breaking waves towards coastline will be formed into longshore current. Longshore current caused sediment transported along the coast, this situation caused abration or sedimentation. The aim of this research was to determine the effect of longshore current towards abration in Pantai Moro. This research using both of primary and secondary data. In primary data, using wave height, period weight, and bed sediment. In secondary data, using ECMWF for wind data among 10 years, Landsat Imagery 7 and 8, river discharged, also tidal data. This research using purpose sampling method. Svendrup Munk Metode Bretchheider (SMB) method used to predict wave height and waves periode in every season, and Digital Shoreline Analysis System (DSAS) used to calculate the abration rate. The result showed the speed of longshore current in the west season was $1,25038 \mathrm{~m} / \mathrm{s}$, in the transition season 1 was $0.71639 \mathrm{~m} / \mathrm{s}$, in the east season was $1,08519 \mathrm{~m} / \mathrm{s}$, and in the transition season 2 was $1,00732 \mathrm{~m} / \mathrm{s}$, which causes abrasion from $2015-2016$ an area of 7,92 ha.

Keyword: Longshore Current, Abrasion, DSAS, Moro Beach

\section{Pendahuluan}

Pantai merupakan daerah pertemuan antara darat, laut dan udara. Oleh karena itu, daerah pantai sangat dipengaruhi oleh gelombang, arus, pasang surut dan aktivitas manusia. Interaksi yang disebabkan oleh faktor oseanografi tersebut dapat menyebabkan terjadinya perubahan garis pantai (Sakka et al, 2014). Sedangkan menurut Nordstrom, K.F et al (1986) menjelaskan bahwa pantai merupakan lingkungan yang dinamis dan selalu berubah. Perubahan tersebut dapat menjadi penyebab kerusakan pada daerah pesisir. Namun pantai akan selalu menuju kesetimbangan sesuai dengan hukum alam. 
Gelombang yang datang dari arah laut dalam akan pecah, kemudian membentuk sudut terhadap garis pantai yang menimbulkan longshore current (Triatmodjo, 1999). Energi yang ditimbulkan longshore current akan membawa material sedimen menuju pantai sehingga akan menyebabkan terhadinya perubahan garis pantai. Kecepatan longshore current tergantung akan tinggi, periode dan sudut datang gelombang yang mendekati pantai.

Pantai Moro merupakan salah satu wilayah pesisir yang terletak di Kecamatan Rowosari, Kabupaten Kendal dan merupakan perairan terbuka yang berbatasan langsung dengan Laut Jawa. Di pantai ini telah dibangun Jetty dibagian hulu Kali Kuto yang menyebabkan pergerakan sedimen menjadi terhambat. Selain itu, pembangunan pelabuhan Sendang Sikucing yang terletak di sebelah timur Pantai Moro turut memberikan pengaruh terhadap transport sedimen. Hal ini menyebabkan gelombang yang datang dari arah timur langsung menuju Pantai Moro dan merupakan salah satu penyebab abrasi yang terjadi di Pantai ini. Menurut Dinas Perikanan dan Kelautan Kendal (2003) dalam Handoyo dan Agus (2015) pantai di kabupaten Kendal mengalami abrasi.

Perubahan garis Pantai Moro dipengaruhi oleh faktor oseanografi, khususnya longshore current yang akan memberikan pengaruh terhadap transpor sedimen disepanjang pantai. Penelitian ini menggunakan metode SMB (Svendrup Munk Metode Bretchheider) untuk peramalan gelombang. Kecepatan longshore current dapat diketahui dengan menggunakann rumus empiris $\mathrm{V}=1,17(\mathrm{~g} \mathrm{Hb}) 1 / 2 \sin \alpha \mathrm{b} \cos \alpha \mathrm{b}$. Sedangkan abrasi pantai dapat diketahui dengan menggunkan metode DSAS (Digital Shoreline Analysis System). Tujuan dari penelitian ini adalah untuk mengetahui pengaruh longshore current terhadap abrasi yang terjadi di Pantai Moro. Dengan demikian dapat diketahui kecepatan dan arah longshore current yang dapat menyebabkan abrasi di Pantai Moro, Kabupaten Kendal, Jawa Tengah.

\section{Materi dan Metode Penelitian}

\subsection{Materi Penelitian}

Materi yang digunakan dalam penelitian ini meliputi data primer dan data data sekunder. Data Primer adalah data yang diperoleh secara langsung, seperti pengukuran data lapangan. Sedangkan data sekunder merupakan data yang diperoleh secara tidak langsung yang berhubungan dengan objek penelitian (Arikunto dan Suharsimi, 1993 dalam Prihanto et al. 2014). Data primer meliputi data gelombang di Pantai Moro 14-16 Desember 2019. Sedangkan data sekunder meliputi data angin ECMWF (European Centre for Medium-Range Weather Forecasts) selama 10 tahun (2010-2019), Citra Landsat 7 dan Landsat 8 dari USGS (United States Geological Survey) dan data debit sungai, data curah hujan, dan data pasang surut.

\subsection{Metode Penelitian}

Metode yang digunakan dalam penelitian ini yaitu metode kuantitatif. Metode kuantitatif merupakan metode ilmiah (scientific) karena telah memenuhi kaidah-kaidah ilmiah yaitu konkrit/empiris, obyektif, terukur, rasional, serta sistematis (Sugiyono, 2011).

\subsection{Metode Penentuan Lokasi}

Penentuan lokasi pengukuran gelombang menggunakan metode area sampling karena danggap dapat mewakili daerah penelitian yang luas (Sugiyono, 2012). Pengukuran data gelombang dilakukan pada satu titik yaitu di koordinat $06^{\circ} 54^{\prime} 11.20^{\prime}$ LS dan $110^{\circ} 02^{\prime} 22.20^{\prime \prime}$ BT dengan kedalaman $1,7 \mathrm{~m}$. Sedangkan teknik pengambilan sampel sedimen dasar menggunkan metode purposive sampling yaitu metode pengambilan sampel yang mempresentasikan keadaan keseluruhan berdasarkan pertimbangan dari peneliti (Sudjana, 1992).

\subsection{Metode Pengukuran dan Pengambilan data}

\subsubsection{Data Gelombang}

Pengukuran gelombang di lapangan dilakukan pada tanggal 14-16 Desember 2019 dengan interval pengukuran setiap 1 jam menggunakan palem gelombang yang di pasang pada kedalaman 1,7m. Data yang diperoleh yaitu berupa tinggi $(\mathrm{H})$ dan periode $(\mathrm{T})$ dan sedangkan untuk mengetahui arah angin menggunakan anemometer. Data tinggi dan periode gelombang yang diperoleh kemudian dianalisis untuk mendapatkan tinggi gelombang signifikan (Hs) dan periode gelombang signifikan (Ts) dengan menggunakan rumus sebagai berikut: $n=33,3 \% \times$ Jumlah data

$\mathrm{Hs}=\frac{(H 1+H 2+\cdots, H n)}{n}$ 
Ts $=\frac{(T 1+T 2+\cdots, T n)}{n}$

\subsubsection{Sedimen Dasar}

Teknik pengambilan sampel sedimen dasar menggunakan sediment grab. Pengambilan sampel sedimen menggunakan dilakukan dengan cara menjatuhkan sedimen grab keperairan dan setelah sampel di dapat maka ditarik kembali dan sampel ditandai berdasarkan lokasi sampling. Sampel sedimen dasar pada penelitian ini dilakukan di 12 titik pengambilan sampel.

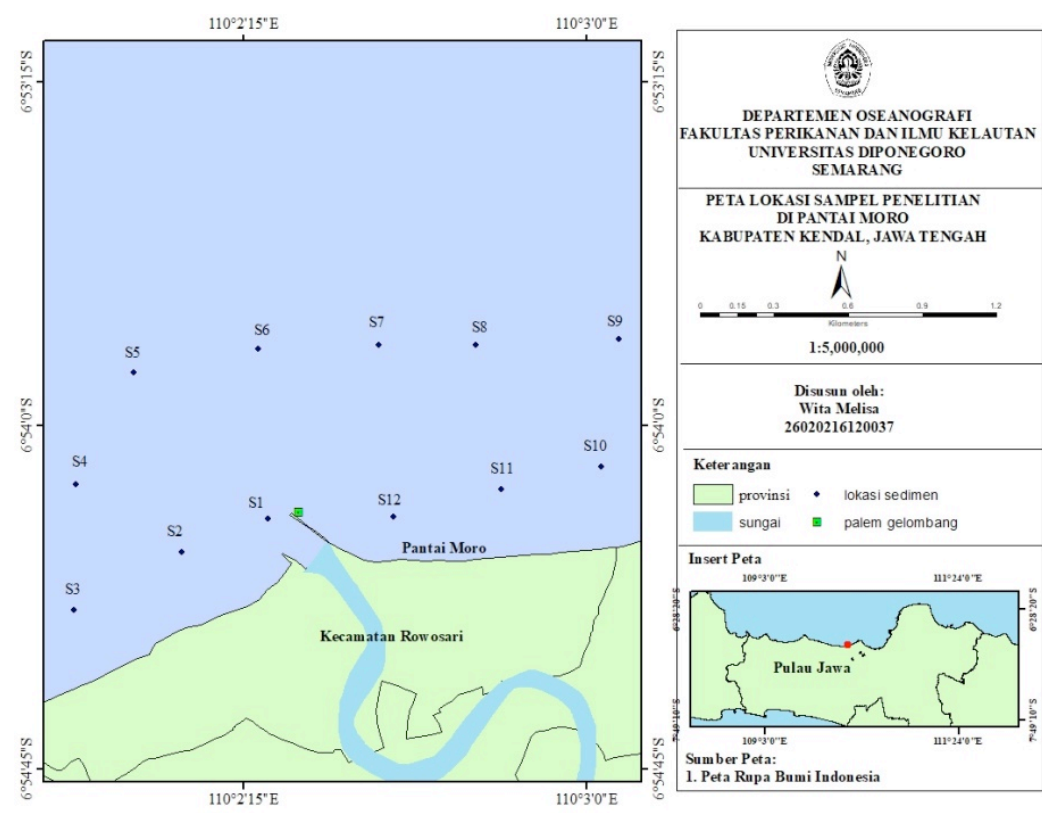

Gambar 1. Peta Titik Lokasi Pengambilan data

\subsection{Metode Pengolahan Data dan Analisis Data}

\subsubsection{Pengolahan Data Gelombang}

Data gelombang yang diperoleh dari hasil pengukuran lapangan dan peramalan gelombang di olah untuk mendapatkan tinggi gelombang representatif (Hs) dan periode gelombang represntatif (Ts). Peralaman gelombang menggunakan data angin yang diperoleh dari ECMWF yang dikonversi menggunakan windrose untuk mengetahui arah angin dominan dan menggunakan metode SMB untuk meramalkan gelombang dilokasi penelitian.

Untuk mengetahui nilai error antara data tinggi dan periode data lapangan dengan data peramalan mengunakan rumus RME (Mean Relative Error). Metode Mean Relative Error (MRE) merupakan metode yang digunakan untuk mengetahui kemiripan data lapangan dan pemodelan (Zaman dan Syarifudin, 2007). Menurut Diposaptono dan Budiman (2006) dapat dihitung dengan Persamaan:

$$
\begin{array}{ll}
\mathbf{R E}=\frac{X a-X b}{X a} & X \mathbf{1 0 0} \% \\
\text { MRE } & =\sum_{0}^{n} \frac{\boldsymbol{R E}}{n} \\
\text { Dimana : } & \\
\text { Re } & \text { : Kesalahan Relatif (Realtive Error) } \\
\text { MRE } & \text { :Rata-Rata Kesalahan Relatif (Mean Relative Error) } \\
\mathrm{Xa} & \text { : Data Pengukuran Lapangan } \\
\mathrm{Xb} & \text { : Data Hasil Peramalan } \\
\mathrm{n} & \text { : Jumlah Data }
\end{array}
$$




\subsubsection{Peramalan Glombang}

Peramalan gelombang menggunakan data angin yang diperoleh dari ECMWF (European Centre for Medium-Range Weather Forecasts). Data angin yang diperoleh diolah menggunakan software WRPLOT untuk mengetahui arah dan keceapatan angin dominan yang ditampilkan dalam bentuk windrose. Sedangkan untuk peramalan gelombang menggunkan metode Svendrup Munk Bretchheider (SMB). Metode Sverdrup Munk Bretschneider (SMB) merupakan metode yang digunakan untuk memperoleh nilai tinggi dan periode gelombang laut signifikan (Mulyadi, 2015).

\subsubsection{Pengolahan Longshore Current (Arah Sejajar Pantai)}

Kecepatan longshore current diperoleh dari hasil perhitungan tinggi gelombang pecah (Hb) dan sudut gelombang pecah $(\alpha b)$ dengan menggunakan rumus empiris (Triadmodjo, 1999)

$$
V=1,17 \sqrt{g H_{b}} \sin a_{b} \cos a_{b}
$$

Keterangan :

$\mathrm{V}=$ Kecepatan longshore current

$\mathrm{g}=$ Percepatan gravitasi

$\mathrm{H}_{\mathrm{b}}=$ Tinggi gelombang pecah

$\alpha_{\mathrm{b}}=$ Sudut datang gelombang pecah

\subsubsection{Pengolahan Data Sedimen}

Pengolahan sampel sedimen dilakukan untuk memperoleh ukuran butir dan penamaan jenis sedimen menggunakan analisa granulometri. Analisis grain size dilakukan dengan metode dry sieving (pengayakan) dan wet sieving (pemipetan) (Buchanan 1979 dalam McIntyre dan Holme 1984). Hasil dari analisa ukuran butir akan dilakukan penamaan sedimen dengan mengklasifikasikan sesuai dengan skala Wentworth untuk selanjutnya dilakukan penamaan dengan menggunakan segitiga Shepard.

\subsubsection{Pengolahan Perubahan Garis Pantai}

Citra tahun 2015-2019 dikoreksi dengan menggunakan software envi untuk mempertajam tampilan citra dan koreksi hamburan awan dan dilanjutkan dengan koreksi menggunkan data pasang surut. Untuk mengetahui besarnya perubahahan garis pantai yang terjadi dilakukan analisa dengan menggunakan perangkat lunak Digital Shoreline Analysis System (DSAS). Digital Shoreline Anaysis System (DSAS) merupakan suatu perangkat lunak yang bekerja pada software Arc Gis yang dikembangkan oleh ESRI dan USGS. Digital Shoreline Anaysis System digunakan untuk menghitung perubahan garis pantai berdasarkan waktu secara statistic dan berbasis geospasial (Istiqomah et al, 2016). Analisa dengan menggunakan metode DSAS terdiri dari tiga tahapan yaitu, pembuatan garis dasar sejajar pantai yang digunakan sebagai garis acuan (baseline), pembuatan transek tegak lurus dengan baseline yang membagi pias-pias garis pantai, dan menghitung tingkat perubahan garis pantai (Umami et al, 2018)

\section{Hasil dan Pembahasan}

\subsection{Gelombang Pengukuran Lapangan}

Pengukuran gelombang lapangan dilaksanakan pada tanggal 14-16 Desember 2019 yang berlokasi di pantai Moro, Kabupaten Kendal.

Tabel 1. Tinggi dan Periode Gelombang Lapangan

\begin{tabular}{ccccc}
\hline No & Keterangan & Maksimum & Signifikan & Minimum \\
\hline 1 & $\mathrm{H}(\mathrm{m})$ & 0,55 & 0,39 & 0,18 \\
2 & $\mathrm{~T}($ detik) & 6,97 & 4,48 & 1,02
\end{tabular}

\subsection{Mawar Angin}

Data yang diperoleh dari ECMWF ditampilkan dalam bentuk mawar angin (windrose) sehingga diperoleh arah dan kecepatan angin dominan selama 10 tahun pada tiap musimnya, yaitu musim barat, musim peralihan 1, musim timur dan musim peralihan 2. Berdasarkan mawar angin pada musim barat angin dominan 
berasal arah barat laut, sedangkan pada musim peralihan 1, musim timur dan musim peralihan 2 angin dominan berasal dari timur laut. arah dan kecepatan angin pada tiap musim selama 10 tahun akan disajikan pada gambar 2

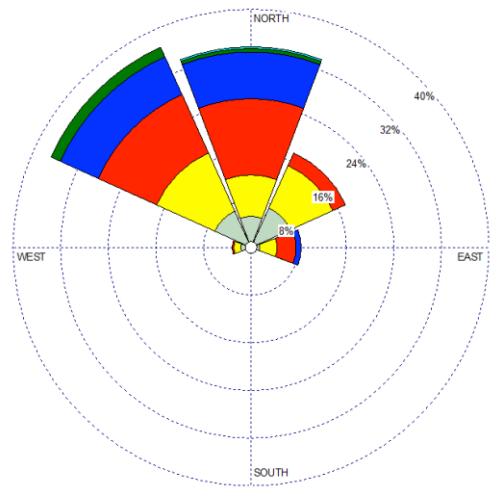

Musim Barat

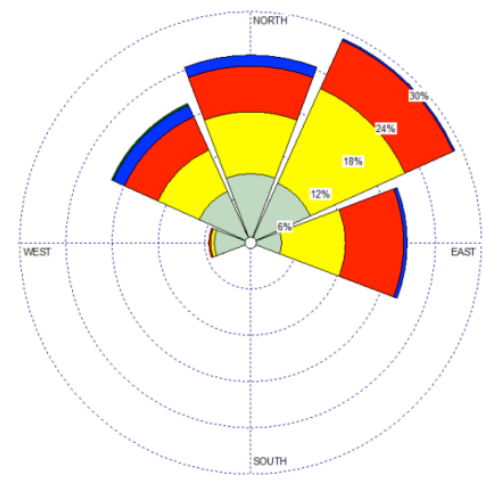

Musim Timur
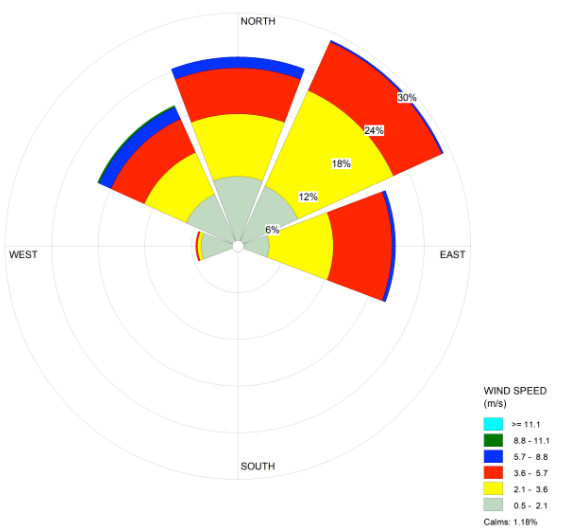

Musim Peralihan 1

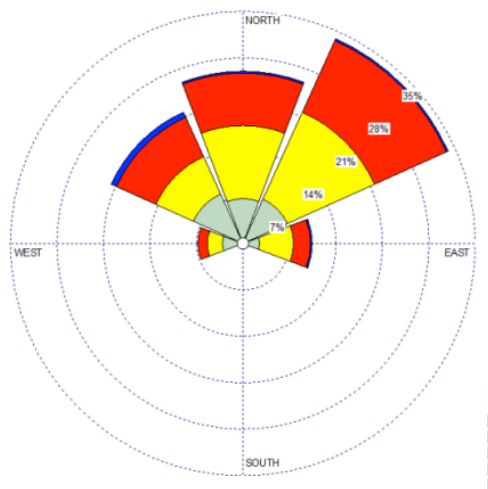

Musim Peralihan 2

Gambar 2. Mawar Angin Tiap Musim Tahun 2010-2019

\subsection{Peramalan Gelombang}

Peramalan gelombang menggunakan pengolahan data angin ECMWF selama 10 tahun (2010-2019), dan menggunakan metode SMB (Svendrup Munk Bretchheider) untuk mendapatkan tinggi dan periode gelombang signifikan. Data angin yang digunakan mempunyai kecepatan $\geq 10$ knot, dimana pada kecepatan angin tersebut yang dapat membangkitkan gelombang. Berikut disajikan hasil pengolahan data peramalan gelombang pada tabel 2 .

Tabel 2. Hasil Peramalan $H s$ dan $T s$

\begin{tabular}{llllllll}
\hline \multirow{2}{*}{ No } & \multirow{2}{*}{ Musim } & \multicolumn{3}{c}{ Hs $(\mathrm{m})$} & \multicolumn{3}{c}{ Ts (det) } \\
\cline { 3 - 7 } & & Max & Mean & Min & Max & Mean & Min \\
\hline 1 & Barat & 0.77 & 0,73 & 0.03 & 7.68 & 4.94 & 0.15 \\
2 & Peralihan 1 & 0.48 & 0.44 & 0.08 & 6.94 & 4.20 & 0.10 \\
3 & Timur & 0.71 & 0.66 & 0.04 & 7.22 & 4.86 & 0.13 \\
4 & Peralihan 2 & 0.63 & 0.57 & 0.01 & 7.08 & 4.52 & 0.12 \\
\hline
\end{tabular}




\subsection{Verifikasi Data Gelombang}

Hasil pengukuran data gelombang lapangan yang dilakukan pada tanggal 14-16 Desember 2019 digunakan untuk memverifikasi data peramalan gelombang. Data lapangan dan data peramalan menggunakan waktu yang sama. Hasil perhitungan gelombang lapangan dan peramalan disajikan dalam tabel 4 .

Tabel 4. Verifikasi Tinggi dan Periode Gelombang Signifikan Lapangan dan Peramalan

\begin{tabular}{ccc}
\hline Gelombang & Hs & Ts \\
\hline Data Lapangan & 0,39 & 4,48 \\
Data Peramalan & 0,52 & 5,74 \\
Rata-rata Error & $33,33 \%$ & $28,12 \%$ \\
\hline
\end{tabular}

\subsection{Gelombang Pecah}

Hasil perhitungan dari peramalan gelombang dengan menggunakan data angin pada setiap musimnya akan di dapatkan tinggi gelombang pecah $(\mathrm{Hb})$, kedalaman gelombang pecah $(\mathrm{db})$, dan sudut gelombang pecah $(\alpha b)$. Berdasarkan hasil perhitungan, berikut disajikan hasil pengolahan pengolahan data gelombang pecah pada tabel 2.

Tabel 3. Tinggi dan Periode Gelombang Hasil Pemodelan Tahun 2010-2019

\begin{tabular}{ccccc}
\hline No & Musim & Hb (m) & db (m) & ab $\left.\mathbf{(}^{\circ}\right)$ \\
\hline 1 & Barat & 0,9401 & 1,0153 & 43,6518 \\
2 & Peralihan 1 & 0,6596 & 0,7783 & 22,1852 \\
3 & Timur & 0,8484 & 0,9502 & 37,5592 \\
4 & Peralihan2 & 0,8096 & 0,9068 & 44,2705 \\
\hline
\end{tabular}

Berdasarkan hasil perhitungan nilai rata-rata error antara pengukuran gelombang lapangan dan peramalan tinggi signifikan yaitu 33,33\% sedangkan nilai rata-rata error periode gelombang lapangan dan periode peramalan yaitu $28,12 \%$. Berdasarkan hasil niali rata-rata error yang menunjukkan kurang dari 50\%, data tersebut dapat digunakan untuk pengolahan data selanjutnya.

\subsection{Longshore Current}

Perhitungan kecepatan longshore current menggunakan data yang telah diperoleh dari perhitungan gelombang pecah. Pantai Moro termasuk kedalam tipe perairan transisi yang memiliki kedalama relative $0,05<$ $\mathrm{d} / 1<0,5$. Gelombang datang yang membentuk sudut $>5^{\circ}$ terhadap garis pantai akan menimbulkan longshore current. Berdasarkan pengolahan data hasil yang diperoleh disajikan dalam tabel 4.

Tabel 4. Hasil Perhitungan Longshore Current

\begin{tabular}{cccc}
\hline No & Musim & V $(\mathbf{m} / \mathbf{s})$ & Keterangan \\
\hline 1 & Barat & 1,25038 & $(-)$ \\
2 & Peralihan 1 & 0,71639 & $(+)$ \\
3 & Timur & 1,08519 & $(-)$ \\
4 & Peralihan 2 & 1,00732 & $(+)$ \\
\hline
\end{tabular}

Pada musim barat kecepatan longshore current sebesar 1,25038 m/s, pada musim peralihan 1 kecepatan longshore current sebesar $0,71639 \mathrm{~m} / \mathrm{s}$, ada musim timur kecepatan longshore current sebesar 1,08519 m/s, sedangkan pada musim peralihan 2 kecepatan longshore current sebesar 1,00732 m/s. Menurut Triadmodjo (1999), arah longshore current akan sesuai dengan arah datangnya gelombang. Berdasarkan hasil sudut datang gelombang setiap musimnya, maka diperoleh arah longshore current di pantai Moro, Kabupaten Kendal. Peta arah longshore current disajikan pada gambar 3 . 

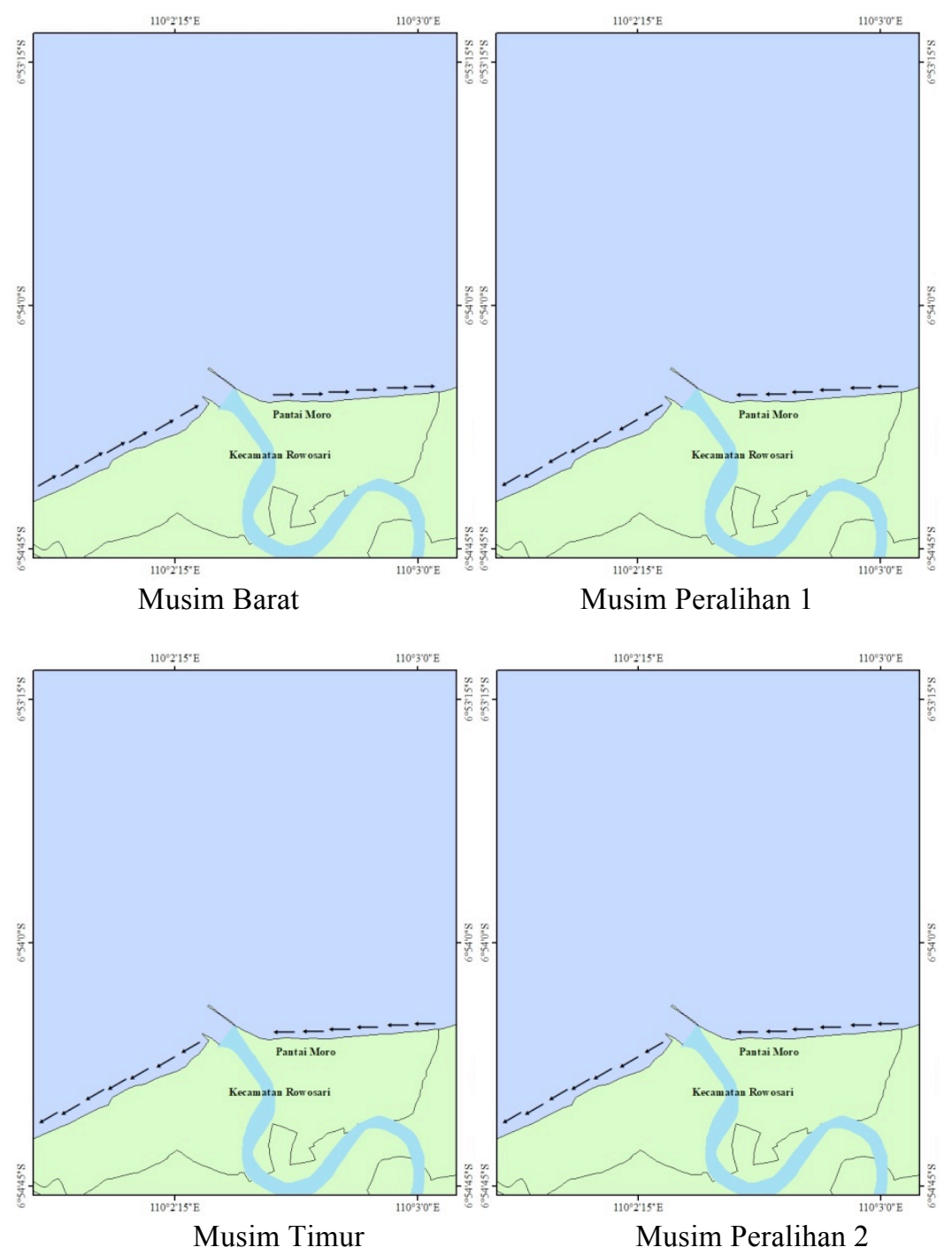

Gambar 3. Arah Longshore Current Tiap Musim

\subsection{Angkutan Sedimen}

Analisa pengolahan sampel sedimen dilakukan di laboratorium Geologi, Fakultas Perikanan dan Ilmu Kelautan Universitas Diponegoro. Berdasarkan hasil pengolahan dan analisis ukuran sampel sedimen di Pantai Moro didominasi oleh jenis lanau. Potensi angkutan sedimen terbesar terjadi pada musim barat yaitu 325,84 $\mathrm{m}^{3} /$ hari atau $294.591,84 \mathrm{~m}^{3} /$ tahun. Sedangkan angkutan sedimen terendah terjadi pada musim peralihan 1 yaitu $114,68 \mathrm{~m} 3 /$ hari atau $104.680,03 \mathrm{~m} 3 /$ tahun.

\subsection{Analisa Abrasi}

Analisa perubahan garis pantai Moro menggunakan citra Landsat 7 dan Landsat dari tahun 2015-2019 yang selanjutnya dilakukan digitasi menggunakan software ArcGis 10.5. Untuk mengetahui perubahan garis pantai yang terjadi menggunakan perangkat lunak DSAS (Digital Shoreline Analysis System).

Berdasarkan perhitungan diketahui bahwa abrasi yang terjadi di Pantai Moro dari tahun 2015-2019 yaitu 7,29 ha dan akresi sebesar 1,04 ha. Bedasarkan nilai EPR dan NSM di pantai Moro. nilai EPR digunakan untuk mengetahui laju perubahan garis pantai sedangkan nilai NSM digunakan untuk menghitung selisih perubahan garis pantai. Hasil yang diperolah yaitu nilai EPR tertinggi 13,24 m/tahun, terendah $-8,91 \mathrm{~m} /$ tahun. Nilai ratarata EPR abrasi yaitu $-3.16 \mathrm{~m} /$ tahun dan niali EPR akresi $2.89 \mathrm{~m} /$ tahun. Sedangkan nilai NSM tertinggi 60,95 m dan terendah $-41,01 \mathrm{~m}$. Nilai rata-rata NSM abrasi yaitu $-13,44 \mathrm{~m}$ dan akresi $11.98 \mathrm{~m}$. Berdasarkan peta 
perubahan garis pantai yang telah diperoleh, dapat diketahui bahwa Pantai Moro mengalami perubahan garis pantai yang di dominasi oleh proses abrasi.

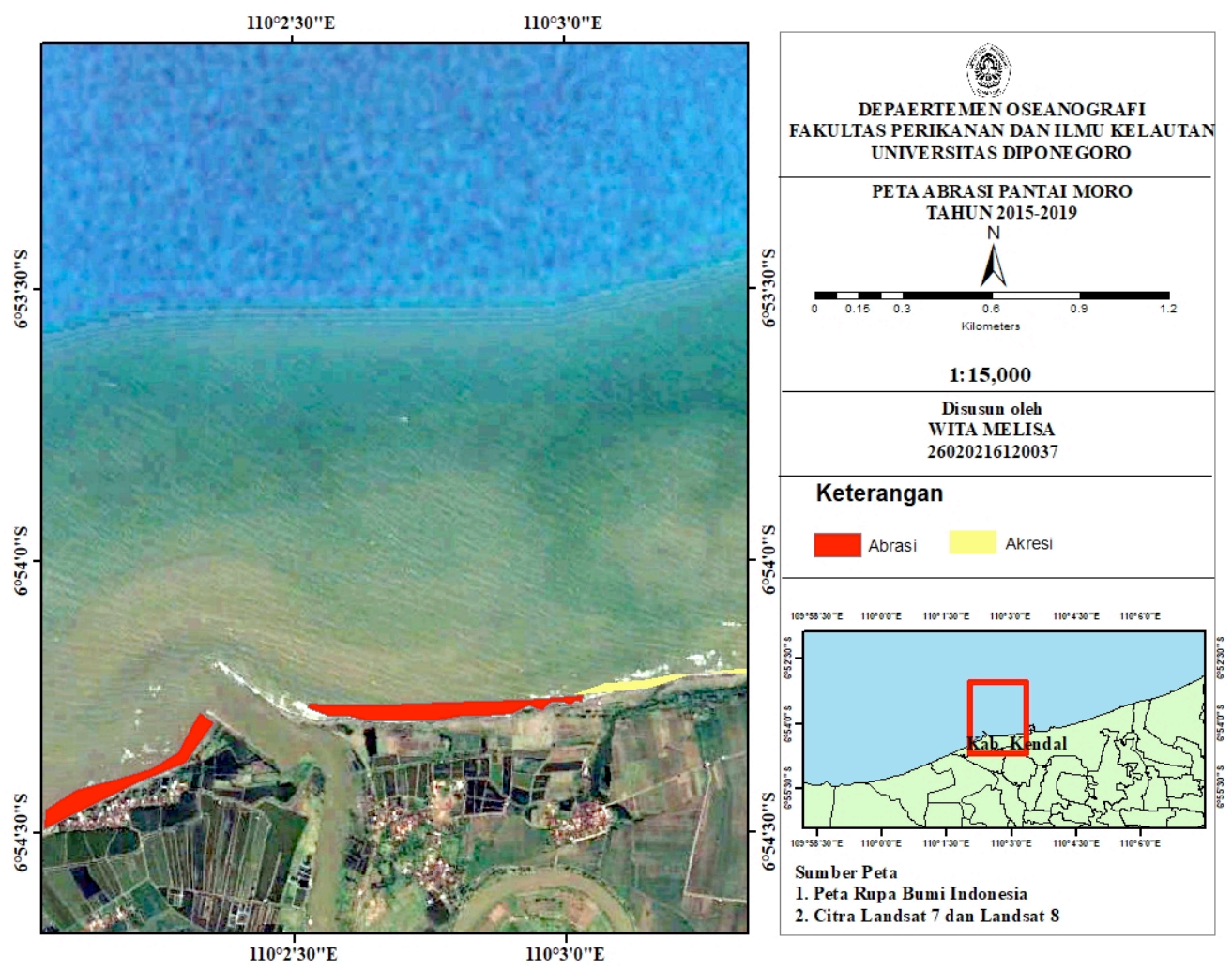

Gambar 4. Peta Perubahan Garis Pantai Moro

\section{Pembahasan}

Daerah penelitian didominasi oleh proses abrasi yang dapat dilihat dari tahun 2015-2019 terjadi proses abrasi sebesar 7,29 ha. Hal ini disebabkan karena karakteristik pantai Moro yang bersifat terbuka terhadap dinamika perairan, sehingga mendapat pengaruh langsung dari arus dan gelombang laut. Selain itu akibat pembangunan pelabuhan Sendang Sikucing dibagian timur menyebabkan gelombang datang kearah pantai Moro menjadi lebih cepat. Karena tidak adanya pelindung pantai dari pengaruh gelombang laut, ketika gelombang besar datang langsung menuju pantai maka akan menyebabkan proses pengikisan terjadi lebih cepat. Menurut Halim et al (2016) proses abrasi dapat dipengaruhi oleh aktivitas manusia seperti penimbunan pantai atau reklamasi untuk keperluan pemukiman, wisata, pelabuhan, maupun pembangunan pelindung pantai.

Ukuran butir sedimen merupakan faktor yang penting dalam mempengaruhi proses sedimentasi, transportasi serta pengendapan yang terjadi dipantai. Perbedaan ukuran butir sedimen akan mempengaruhi kecepatan transportasi sedimen, semakin besar ukuran butir sedimen lokasi pengendapannya akan dekat dengan lokasi sumbernya, namun semakin halus ukuran butir sedimen akan semakin memudahkannya tertransportasi dan menjauhi lokasi asalnya. Menurut Yasin et al (2016) dalam Gemilang (2018), analisa granulometri merupakan suatu metode yang digunakan untuk menganalisis ukuran butir sedimen. Berdasarkan analisa ini dapat diketahui proses pelapukan, abrasi, sedimentasi serta asalnya tertransportasi.

Menurut Fajri (2012) dalam Lilian et al (2013) ukuran butir sedimen memiliki hubungan erat dengan abrasi pantai, semakin halus ukuran butir sedimen akan menyebabkan semakin luasnya pantai mengalami abrasi. Sedangkan menurut Thurnan (1983) dalam Mawardi (2016) pergerakan sedimen akan dipengaruhi oleh kecepatan arus dan ukuran butir sedimen. Berdasarkan hasil yang telah diperoleh, lokasi penelitian di dominasi oleh sedimen jenis lanau yang memnudahkannya tertrasnportasi dari sumber asalnya. Hal ini akan mempermudah terjadinya abrasi di pantai Moro.

Karakteristik pantai Moro yang sangat dinamis dan fluktuatif menyebabkan rentannya terjadi perubahan garis pantai. Arus sejajar pantai merupakan salah satu penyebab dalam pembentukan morfologi pantai (Dahuri et al. 2008). Arus menyusur pantai (longshore current) akan menimbulkan pergerakan massa air yang disebabkan oleh gelombang laut akan berberak menuju pantai dengan sudut datang gelombang tertentu. Gelombang yang 
datang kearah pantai akan pecah seiring berkurangnya kedalaman laut. Gelombang pecah tersebut akan menimbulkan arus yang akan menggerakkan sedimen. Menurut Triadmodjo (1999) parameter utama dalam menentukan kecepatan longshore current yaitu tinggi dan sudut datang gelombang.

Arus sejajar pantai di pantai Moro lebih dominan menuju kearah barat. Longshore current terbesar terjadi pada musim barat yaitu $1,25038 \mathrm{~m} / \mathrm{s}$ yang mentrasnportkan sedimen sebesar 325,84m3/harinya atau 296.591,84m3/tahunnya. Berdasarkan penelitian yang dilakukan oleh Praptama (2018) di Pantai Depok Kabupaten Pekalongan, pada musim barat kecepatan longshore current yaitu $1,184 \mathrm{~m} / \mathrm{s}$ yang mentranspor sedimen 452,335 m3/hari dan 165.102,446 m3/tahun.

Dari peta perubahan garis pantai dapat dilihat bahwa di pantai Moro di dominasi oleh proses abrasi yang mendapat pengaruh langsung dari gelombang yang datang langsung menuju kearah pantai. Selain itu pengaruh transpor sedimen yang terjadi disetiap hari dan musim juga berpengaruh terhadap kemunduran garis Pantai Moro. Menurut Yuni et al (2014) proses perubahan garis pantai sangat dipengaruhi oleh proses transport sedimen dan arus sejajar pantai yang dibangkitkan oleh gelombang pecah.

\section{Kesimpulan}

Berdasarkan penelitian yang telah dilakukan didapatkan kesimpulan yaitu abrasi yang terjadi dipantai Moro terjadi karena pengaruh longshore current. Kecepatan longshore current pada musim barat sebesar $1,25038 \mathrm{~m} / \mathrm{s}$, pada musim peralihan 1 sebesar $0,71639 \mathrm{~m} / \mathrm{s}$, pada musim timur sebesar $1,08519 \mathrm{~m} / \mathrm{s}$, dan pada musim peralihan 2 sebesar 1,00732 m/s, yang menyebabkan abrasi dari tahun 2015-2019 seluas 7,29 ha. Hasil pengolahan ukuran butir sedimen yang didominasi oleh jenis lanau turut memberikan pengaruh terhadap proses abrasi sehingga berlangsung dengan cepat.

\section{DAFTAR PUSTAKA}

Dahuri, R. J. Rais, S.P. Ginting dan M.J. Stepu. 1996. Pengelolaan Sumberdaya Wilayah Pesisir dan Lautan Secara Terpadu. Jakarta: PT Paradya Paramita. $328 \mathrm{hlm}$

Diposaptono, S dan Budiman. 2006. Tsunami. Ed. 2, Penerbit Buku Ilmiah Populer, Bogor, 300 hlm.

Gemilang, Wisnu A., Ulung J. Wisha., Guntur A. Rahmawan dan Ruzana Dhiauddin. 2018. Karakteristik Sebaran Sedimen Pantai Utara Jawa Studi Kasus: Kecamatan Brebes Jawa Tengah. Jurnal Kelautan Nasional, 13 (1): 65-74.

Halim., Halili., La Ode Alirman Afu. 2016. Studi Perubahan Garis Pantai dengan Pendekatan Peginderaan Jauh di Wilayah Pesisir Kecamatan Soropia. Jurnal Sapa Laut, 1(1) : 24-31

Handoyo, Gentur., Agus A.D Suryoputro. 2015. Kondisi Arus dan Gelombang pada Berbagai Kondisi Morfologi Pantai di Perairan Pantai Kendal Provinsi Jawa Tengah. Jurnal Kelautan Tropis, 18 (1) : 33-37

Holme, M.G. and N.D. McIntyre. 1984. Methods for Study of Marine Benthos. 2nd ed., Blackwell Scientific Publication, Oxford, 387p.

Istiqomah, F., Sasmito B. dan Amarrohman, F. J. 2016. Pemantauan Perubahan Garis Pantai Menggunakan Aplikasi Digital Shoreline Anaysis System (DSAS) Studi Kasus: Pesisir Kabupaten Demak. Jurnal Geodesi Undip, 5 (1) : 2337-845x.

Lilian, Anna; Mubaeak; Rifardi. 2013. Analisis Sedimen dan Perubahan Garis Pantai Utara Pulay Rangsang Kabupaten Kepulauan Meranti. Universitas Riau, 1 (1).

Mawardi. 2016. Inovasi Mengatasi Pendangkalan pada Pelabuhan Tapak Paderi Kota Bengkulu. Jurnal Inersia, 8 (1)

Mulyadi, J. dan Apriansyah. 2015. Studi Variabilitas Tinggi dan Periode Gelombang Laut Signifikan di Selat Karimata. Positron., V(1): $19-25$.

Nordstrom,K.F., Paul A.G., Nobert P.P., Orrin H.P.Jr., Orrin J.P.Sr. and William J.N. 1986. Living with the New Jersey Shore, Duke University Press, Durham, 193 p.

Prihanto, Dimas Nugroho Ari., Ibnu Pratikto., Irwani. 2015. Studi Kesesuaian Wisata di Pantai Sendang Sikucing Kabupaten Kendal Sebagai Objek Wisata Rekreasi Pantai. . Jurnal Marine Research, 3 (3): 332 341

Sakka, Paharuddin dan Rupang, E. (2014). Analisis Kerentanan Pantai Berdasarkan Coastal Vulnerability Index (CVI) di Pantai Kota Makassar. Jurnal Ilmu Kelautan Dan Perikanan, 24(3), 49-53.

Sudjana, M. M. 1992. Metode Statistika. Tarsito. Bandung

Sugiyono 2011. Memahami Penelitian Kualitatif. Alfabeta, Bandung

Sugiyono. 2012. Metode Penelitian Kuantitatif Kualitatif dan R\&D. Alfabeta, Bandung, $32 \mathrm{hlm}$

Triatmodjo, Bambang. 1999. Teknik Pantai. Beta Offset, Yogyakarta, 397 hlm. 
Umami, Khairul, Syawaludin A. Harahap, Mega Laksmini Syamsudin, Sunarto. 2018. Aplikasi Citra Landsat dalam Analisa Perubahan Garis Pantai. Studi Kasus di Pesisir Sayung, Kabupaten Demak, Jawa Tengah. Seminar Nasional Geomatika 2018: Penggunaan dan Pengembangan Produk Informasi Geospasial Mendukung Daya Saing Nasional

Yuni, Syaridah Meurah., Ichsab Setiawan., Okvita Maufiza. 2014. Solusi Analitik Model Perubahan Garis Pantai Menggunakan Transformasi Laplace. Jurnal Gradien, 10(2) : 1005-2013

Zaman, B., \& Syafrudin. (2007). Model Numerik 2-D (Lateral \& Longitudinal) Sebaran Polutan Cadmium(Cd) Di Muara Sungai (Studi Kasus: Muara Sungai Babon, Semarang). Jurnal Presipitasi, $3(2), 1-8$. 